\title{
Frequency of lower extremity artery disease in type 2 diabetic patients using pulse oximetry and the ankle- brachial index
}

\author{
Mosquera-Fernández Abián¹, Balboa-Barreiro Vanesa², Bellido-Guerrero Diego ${ }^{3}$, González-Sagrado \\ Manuel $^{4}$, Vale-Carrodeguas Maria ${ }^{5}$, Veiga-Seijo Raquel2 ${ }^{2}$ González-Martín Cristina ${ }^{2}{ }^{\circledR}$ \\ 1. Department of Health Sciences. Faculty of Nursing and Podiatry. University of A Coruña (UDC) Ferrol Campus, 15471, Ferrol, Spain. \\ 2. Rheumatology and Public Health Research Group, Nursing Research and Health Care, Biomedical Research Institute of A Coruña (INIBIC), Complejo \\ Hospitalario Universitario de A Coruña (CHUAC), SERGAS, University of Coruña (UDC), As Xubias 84, 15006 A Coruña, Spain. \\ 3. Coordinator of the Endocrinology and Nutrition Unit Ferrol Naval Hospital (Ferrol Health Area). Department of Health Sciences. University of A Coruña \\ (UDC). Ferrol Campus, 15471, Ferrol, Spain. \\ 4. Research Support Unit. Rio Hortega University Hospital. Dulzaina 2. 47012, Valladolid, Spain. \\ 5. Nurse at the Ferrol University Hospital Complex (Ferrol Health Area). Avda. de la Residencia s/n. 15405 Ferrol, Spain.
}

$\square$ Corresponding author: Cristina González-Martin, Rheumatology and Public Health Research Group, Nursing Research and Health Care, Biomedical Research Institute of A Coruña (INIBIC), Complejo Hospitalario Universitario de A Coruña (CHUAC), SERGAS, University of Coruña (UDC), As Xubias 84, 15006 A Coruña, Spain. E-mail: cristina.gmartin@udc.es.

(C) The author(s). This is an open access article distributed under the terms of the Creative Commons Attribution License (https://creativecommons.org/licenses/by/4.0/). See http://ivyspring.com/terms for full terms and conditions.

Received: 2021.02.01; Accepted: 2021.04.12; Published: 2021.05.27

\begin{abstract}
Objectives: To determine the of undiagnosed lower extremity artery disease using the pulse oximetry in a type 2 diabetic population sample.

Methods: Observational, cross-sectional, descriptive study that included 594 type 2 diabetic patients, with no previous history of lower extremity artery disease. Medical history, physical examination, determination of the ankle-brachial index (portable Doppler) and measurement of oxygen saturation in upper and lower extremities (pulse oximeter) were performed.

Results: Frequency of lower extremity artery disease determined by ankle-brachial index was $18.4 \%$. No significant correlations were detected between oxygen saturation and the ankle-brachial index except for the relationship between ankle-brachial index vs. oxygen saturation at $30 \mathrm{~cm}$ lower limb elevation vs. the supine position at no elevation $(0 \mathrm{~cm})$ in subjects under the age of 40 . Pulse oximetry showed little diagnostic value in the screening of lower extremity artery disease. A relationship between lower extremity artery disease and age has been found. Its diagnosis was associated with a lower body mass index and lower systolic blood pressure in the lower extremities and higher in the upper extremities.

Conclusions: We conclude that pulse oximetry is not useful in the screening for asymptomatic lower extremity artery disease in type 2 diabetics.
\end{abstract}

Key words: diabetes; pulse oximetry; lower extremity artery disease

\section{Introduction}

Excess glucose in the blood causes dysfunction and failure of various organs, but particularly blood vessels and nerves. Its evolution is usually asymptomatic (it is estimated that between $30 \%$ and $50 \%$ of patients are not diagnosed), which means that at the time of diagnosis it is already possible to verify a certain degree of vascular deterioration. Currently, diabetes mellitus (DM) is diagnosed according to the plasma glucose value (fasting or 2 hours after an oral glucose overload) or according to the glycated hemoglobin value $(\geq 6.5 \%)$ [1]

Recently, a prevalence of diagnosed DM in the United States of $8.2 \%$ has been estimated, calculating that it could reach $10.5 \%$ (more than 34 million people) if undiagnosed cases are added to those diagnosed [2]. Globally, DM continues to increase throughout the world unevenly depending on the country and affected population. In fact, it is expected 
that by 2040 there will be 642 million people with DM around the world, further increasing the associated health expenditure, which was already estimated at 673 billion dollars in 2015 [2-3].

On the other hand, PAD is the leading cause of morbidity and mortality in diabetics. It is a progressive, systemic disease that causes arterial stenosis mainly in the lower limb. It is a good marker of systemic atherosclerosis and an important predictor of cardiovascular morbidity and mortality. Although the etiology of atherosclerosis is multifactorial, DM constitutes one of its main risk factors [4]. Its prevalence increases significantly with age, in such a way that from the $5.6 \%$ detected in people between 38 and 59 years of age it goes to $15.9-29 \%$ between 60 and 69 years [5-7]. Currently, it affects more than 200 million people around the world, being one of the most prevalent pathologies and with the highest morbidity and mortality in the world that causes approximately 37.3 billion dollars related to cardiovascular disease and DM [8-10]. Epidemiological studies such as REACH-E, FRENA and AIRVAG analyze the impact of PAD in different vascular territories and affirm that the distribution of coronary heart disease is broader than cerebrovascular disease and that those with PAD in addition to having poorer control they tend to present new ischemic episodes in another vascular territory [11-13]. In the AIRVAG study, for example, $21 \%$ of the individuals with PAD also had asymptomatic vascular involvement in another vascular territory, and in the VITAMIN study, the prevalence of PAD was $21.3 \%$ in non-diabetics [14].

Both known and unknown PAD are more frequent in diabetics than in the general population. In this sense, published data differ markedly and can even vary among diabetics followed in primary and specialized care. As an example, in primary care centers of Catalonia the prevalence of unknown PAD reported according to the Ankle-Brachial Index (ABI) was of $21.5 \%$ among type 2 diabetics with a mean age of 65.3 years.

However, in consultations of Endocrinology throughout Spain among diabetics (type 1 and type 2) with an average age of 59 years, the prevalence of PAD was 37.3\% [15-16]. Among diabetics aged 50-85 years seen in internal medicine consultations (MERITO study), the prevalence of unknown PAD was $26.2 \%$ and in diabetics older than 70 years followed in specialized care (internal medicine, geriatrics and endocrinology) the prevalence of PAD was $60.6 \%$ (in $41.2 \%$ of asymptomatic cases), which raised up to $71 \%$ based on ABI [17-18].

ABI is a bloodless, simple, cheap and reproducible test with high specificity to identify an obstruction in the arteries of the lower limb, making the diagnosis of lower extremity artery disease (LEAD) possible. It is routinely used in disease screening, allowing the identification of asymptomatic patients in whom early detection would make it possible to initiate adequate treatment, control of cardiovascular risk factors and even modify risk stratification. The American Diabetes Association (ADA) recommends its use in the initial screening for PAD among those who present signs or symptoms and asymptomatic cases with clinical suspicion [19-20]. However, ABI has sometimes shown a low sensitivity, it has not been able to detect asymptomatic patients and falsely high values have been obtained in the presence of arterial calcification or stenosis of the subclavian artery [21-24]. For this reason, and because $\mathrm{ABI}$ measurement requires prior training and is time-consuming is often not performed during routine daily practice.

The definitive method or "gold standard" for diagnosing PAD is contrast angiography because of its ability to provide detailed information about arterial anatomy. However, contrast angiography is invasive and carries some risk.

On the other hand, although ABI is not the "gold standard" its diagnosis, it is routinely used in daily practice as it is a cheap, simple and painless method.

An ABI> 0.90 has a sensitivity of $75 \%$ and a specificity of $86 \%$ for the diagnosis of LEAD [25]. Its sensitivity is lower in diabetic patients or patients with terminal chronic kidney disease (CKD) due to calcification of the middle layer [26]. Patients with borderline ABI (0.90-1.00) have to undergo additional diagnostic tests.

Hence, there is a need for non-invasive LEAD diagnostic techniques, easy to perform, cost-effective and able to detect asymptomatic LEAD. In this sense, pulse oximetry has been proposed as a screening tool for LEAD with contradictory results. It has been suggested that it could have greater sensitivity and as much accuracy as ABI [27-29], but on the other hand previous research did not find significant differences in pulse oximetry based on the presence of carotid plaques depending on pathological $\mathrm{ABI}$ values or carotid intima-media thickness [29].

Therefore, the main goal of this study is to determine the frequency of undiagnosed LEAD using the pulse oximetry in a type 2 diabetic population sample. The secondary outcome of the study is to:

- Application of pulse oximetry in LEAD screening;

- Detect LEAD using ABI in the sample studied;

- Study the relationship between LEAD and different epidemiological-clinical variables; 
- Determine the correlation between $\mathrm{ABI}$ and oxygen saturation $\left(\mathrm{SaO}_{2}\right)$.

\section{Experimental Section}

A cross-sectional observational study was carried out in the outpatient clinics of the Endocrinology and Nutrition Service of the Hospital Naval of Ferrol (Ferrol Health Area) from May 2016 to June 2018.The inclusion criteria were type 2 diabetic patients with no previous diagnosis of LEAD who attended these consultations during the study period and who signed the informed consent. The exclusion criteria were Raynaud disease, vasculitis and claudication symptoms. The sample size was 594 patients, which allowed for calculation of the prevalence and $95 \%$ confidence interval (CI) of LEAD with a precision of $3 \%$ for a significance level of 0.05 . The patients who participated in the study were included consecutively. Furthermore, all participants received nutritional counseling. For this purpose, there was a nurse in charge who did this counseling.

\section{Measurements}

The participants were recruited by the Endocrinology and Nutrition specialists. Both, the information gathering and the examinations were carried out in the Service's own external consultations. Sociodemographic variables (age, sex), anthropometric variables (body mass index (BMI), waist circumference, HbA1c, dyslipemia, LDLcholesterol, total cholesterol, arterial hypertension, smoking habits, symptoms of neuropathy through the diapason and clinical variables systolic blood pressure (BP) in the lower right and lower left extremity in the supine position. Systolic and diastolic BP were collected from all participants recruited in a sitting and supine position as well as the presence of peripheral pulses). All patients had ABI measured using a bidirectional portable Doppler (Mini Doppler, model ES-100X® Hadeco Inc. Kawasaki, Japan) at 8 $\mathrm{MHz}$. With the patient in the supine position, the systolic BP of both arms was determined using an appropriate pressure cuff that was placed above the antecubital fossa. Systolic BP was measured at the level of the pedial dorsal and posterior tibial artery. ABI was calculated for each lower limb.

ABI values lower than 0.90 [30] were considered pathological and diagnostic of LEAD. In addition, two measurements of $\mathrm{SaO}_{2}$ were made with a digital pulse oximeter (Onyx ${ }^{\circledR}$ 9500, Nonin Medical Inc. Plymouth, $\mathrm{MN}, \mathrm{USA}$ ), one at the great toe of each foot in the supine position (horizontal) and another measurement with the limb elevated $30 \mathrm{~cm}$. $\mathrm{SaO}_{2}$ was also recorded at both index fingers (upper limb). Regarding the results of pulse oximetry, the $\mathrm{SaO}_{2}$ difference in the great toes compared to index fingers (toe to finger TTF) and the difference in $\mathrm{SaO}_{2}$ of the great toes with the lower limb elevated $30 \mathrm{~cm}$ (T30) compared to the supine position at no elevation (T0) were measured.

Thus, according to previous research [28-29] it was considered pathological:

- A decrease in $\mathrm{SaO}_{2}$ greater than $2 \%$ at the great toes measured in the supine position (no elevation) compared to the highest $\mathrm{SaO}_{2}$ at both index fingers.

- A decrease in $\mathrm{SaO}_{2}$ greater than $2 \%$ at the great toes with the lower limb elevated $30 \mathrm{~cm}$ (T30) compared to the measurement at the great toe of the same foot in the supine position at no elevation (T0).

The usefulness of each of these measurements for LEAD screening was evaluated compared to ABI.

A calibrated thermohygrometer was used in the room where the measurements were taken. The parameters considered as normal were: humidity of $10-80 \%$ and temperature of $20-26{ }^{\circ} \mathrm{C}$. Between each participant, these parameters were checked to be the same in all the exploration.

The statistical analysis was performed with the SPSS version 24.0 program. For the study of the diagnostic tests, the EPIDAT version 3.1 program for epidemiological analysis of tabulated data was used. A descriptive analysis of all the parameters analyzed was carried out. The quantitative variables were described as mean \pm standard deviation (SD) and their normality established with the Kolmogorov-Smirnov test. The qualitative variables were described by absolute frequencies and percentages. The prevalence of LEAD was determined according to the ABI together with its 95\% CI. Differences between patients with or without LEAD were analyzed. The comparison of means was carried out by means of the Student's $t$ test or the Mann-Whitney test, as appropriate. The association of qualitative variables was estimated with the Chi-square statistic. Using the data obtained in the lower limbs, the correlation of TTF and T30-T0 with ABI was determined using Pearson's linear correlation coefficient or Spearman's Rho. The concordance of both indices with the ABI for the diagnosis of LEAD was also determined using the Kappa index. The area under the ROC curve (AUC), and the sensitivity, specificity, predictive values, and likelihood ratios were calculated, along with their 95\% CI

\section{Ethical-legal aspects}

At all times, the ethical standards for the ethical evaluation of epidemiological studies and biomedical 
research in human subjects were followed. On the other hand, the information regarding the identification of the participants was considered confidential for all purposes so that their identity could not be revealed or disclosed in accordance with the provisions of the Organic Law on Protection of Personal Data. Furthermore, the participants were informed of the purpose of the study and their informed consent was obtained respecting their right to privacy $\mathrm{ABI}$ and digital pulse oximetry are both non-invasive harmless screening procedures tests.

The study was approved by the Institutional Ethics Committee (CE 07/2016). All participants signed informed consents.

Privacy of patients as well as data confidentiality were protected at all times.

\section{Results}

A total of 594 patients (1188 lower limbs) were included. The general characteristics of the sample according to sex are shown in Table 1 . Mean age was $62.9 \pm 11.0$ years. 266 women $(44.8 \%)$ and 328 men $(55.2 \%)$ were studied. The BMI presented a mean of $30.7 \pm 6.3 \mathrm{~kg} / \mathrm{m}^{2}$, with a $49.7 \%$ and a $34.1 \%$ classified as obese and overweight respectively. $36.4 \%$ of the sample smoked and $18.2 \%$ were ex-smokers. The mean ABI was $1.07 \pm 0.25$ in the right lower limb and $1.04 \pm 0.24$ in the left lower limb, with the prevalence of LEAD (ABI <0.90) of $18.4 \%$ (95\% CI: $15.1 \%-21.5 \%$ ). $8.4 \%$ of the sample showed LEAD in both lower limbs. Regarding to the smoking habits, 36.4\% smoked, $45.4 \%$ didn't smoke and $18.2 \%$ ex-smoked.

Systolic BP in the upper limbs, of both (seated and supine position) were significantly higher in the group diagnosed with LEAD, while the BP measured in the lower limbs was significantly lower. There were no differences in brachial diastolic BP. Although there were not significant differences, peripheral pulses were present slightly more often in subjects without diagnosis of LEAD (Table 2). Regarding the maximum value of $\mathrm{SaO}_{2}$ at both index fingers and $\mathrm{SaO}_{2}$ at both great toes in the supine position and at $30 \mathrm{~cm}$ elevation, not statistically significant differences were detected between patients with or without diagnosis of LEAD according to ABI (Table 2).

To assess the correlation of the measurements made with the pulse oximeter and the $\mathrm{ABI}$ in the diagnosis of LEAD (TTF and T30-T0). The results obtained for each lower limb were evaluated, comparing them with the $\mathrm{ABI}$ results obtained for the same lower limb. ABI was pathological in 159 lower limbs (13.6\%). A decrease of more than 2\% was observed in the $\mathrm{SaO}_{2}$ at the great toe compared to the $\mathrm{SaO}_{2}$ at the index finger in $113(9.8 \%)$ lower limbs, and a decrease of more than $2 \%$ in the $\mathrm{SaO}_{2}$ at the great toe at $30 \mathrm{~cm}$ elevation compared to the supine position in 98 (9.1\%) lower limbs. Combining these last two criteria, a pathological result was obtained by pulse oximetry in $207(17.9 \%)$ lower limbs. Table 3 shows the concordance, correlation, and validity indices of pulse oximetry with respect to ABI. The TTF and T30-T0 values did not show correlation with the ABI, with zero agreement. Both parameters showed high values of specificity and negative predictive value, but low values of sensitivity and positive predictive value.

The area under the curve (AUC) was 0.525 (95\% $\mathrm{CI}=0.476-0.573)$ for $\mathrm{TTF}$ and $0.504(95 \% \mathrm{CI}=$ 0.454-0.553) for T30-T0. These values were similar regardless of the age and gender of the patients (Table $4)$.

\section{Discussion}

In the present study, we have found data on mean age and BMI very similar to those obtained by Pellitero et al. $\left(62 \pm 7\right.$ years and $31.5 \mathrm{~kg} / \mathrm{m}^{2}$, respectively) [29]. The mean BMI of the sample corresponds to type I obesity, being higher in women, as is also reported by the majority of studies carried out among Spanish adults according to the Spanish Society for the Study of Obesity (SEEDO) [31-32]. In this sense, the ERICE study describes a higher prevalence of obesity in women, with a difference compared to men that is accentuated after the age of 50 [33].

Table 1. General characteristics of the sample

\begin{tabular}{|c|c|c|c|c|}
\hline & $\begin{array}{l}\text { Total } \\
(\mathrm{n}=594)\end{array}$ & Men $(n=328)$ & $\begin{array}{l}\text { Women } \\
(n=266)\end{array}$ & $\mathrm{p}$ \\
\hline & Mean \pm SD & Mean \pm SD & Mean \pm SD & \\
\hline Age (years) & $62.9 \pm 11.0$ & $62.1 \pm 10.5$ & $64 \pm 11.6$ & 0.037 \\
\hline Body Mass Index $\left(\mathrm{Kg} / \mathrm{m}^{2}\right)$ & $30.7 \pm 6.3$ & $29.8 \pm 5.5$ & $31.7 \pm 7.1$ & $<0.001$ \\
\hline Waist circumference (cm) & $101.2 \pm 14.7$ & $102.1 \pm 13.6$ & $100.1 \pm 15.9$ & 0.108 \\
\hline $\mathrm{HbA1c}$ & $8.2 \pm 1.7$ & $8.2 \pm 1.6$ & $8.2 \pm 1.8$ & 0.441 \\
\hline LDL-cholesterol & $98.2 \pm 35.0$ & $98.7 \pm 33.3$ & $99.8 \pm 37.4$ & 0.554 \\
\hline Total cholesterol & $174.6 \pm 42.1$ & $171.5 \pm 42.0$ & $179.1 \pm 42.2$ & 0.164 \\
\hline \multicolumn{5}{|l|}{ Diapason } \\
\hline Left & $4.5 \pm 2.6$ & $4.2 \pm 2.6$ & $4.9 \pm 2.5$ & 0.000 \\
\hline Right & $4.5 \pm 2.6$ & $4.2 \pm 2.7$ & $4.9 \pm 2.4$ & 0.001 \\
\hline \multicolumn{5}{|l|}{ Systolic BP in LL (mmHg) } \\
\hline Right & $157.3 \pm 39.7$ & $159.6 \pm 42$ & $154.6 \pm 36.6$ & 0.128 \\
\hline Left & $153.1 \pm 38.0$ & $155.7 \pm 42.1$ & $149.9 \pm 32.1$ & 0.061 \\
\hline $\begin{array}{l}\text { Systolic brachial BP (seated) } \\
(\mathrm{mmHg})\end{array}$ & $146.1 \pm 20.8$ & $145.4 \pm 19.9$ & $146.9 \pm 22$ & 0.398 \\
\hline $\begin{array}{l}\text { Diastolic brachial BP (seated) } \\
(\mathrm{mmHg})\end{array}$ & $79.3 \pm 10.2$ & $78.8 \pm 10.1$ & $79.8 \pm 10.3$ & 0.270 \\
\hline $\begin{array}{l}\text { Systolic brachial BP (supine) } \\
(\mathrm{mmHg})\end{array}$ & $148.4 \pm 21.3$ & $148.4 \pm 21.3$ & $148.2 \pm 21.4$ & 0.902 \\
\hline $\mathrm{SaO}_{2}$ index finger $(\%)$ & $96.2 \pm 1.9$ & $96.1 \pm 1.9$ & $96.4 \pm 2.1$ & 0.121 \\
\hline \multicolumn{5}{|c|}{$\mathrm{SaO}_{2}$ index finger (supine) (\%) } \\
\hline Right & $96.2 \pm 2.8$ & $96.3 \pm 2.7$ & $96.2 \pm 3$ & 0.816 \\
\hline Left & $96.3 \pm 2.7$ & $96.1 \pm 2.9$ & $96.5 \pm 2.4$ & 0.121 \\
\hline \multicolumn{5}{|c|}{$\mathrm{SaO}_{2} \mathrm{LL} 30 \mathrm{~cm}$ elevation $(\%)$} \\
\hline Right & $95.5 \pm 3.9$ & $95.6 \pm 3.2$ & $95.3 \pm 4.6$ & 0.397 \\
\hline Left & $95.6 \pm 3.6$ & $95.5 \pm 3.7$ & $95.7 \pm 3.3$ & 0.469 \\
\hline
\end{tabular}




\begin{tabular}{lllll}
\hline & $\begin{array}{l}\text { Total } \\
(\mathrm{n}=594)\end{array}$ & Men $(\mathrm{n}=328)$ & $\begin{array}{l}\text { Women } \\
(\mathrm{n}=266)\end{array}$ & $\mathrm{p}$ \\
\cline { 2 - 4 } & Mean \pm SD & Mean \pm SD & Mean \pm SD & \\
\hline Ankle-Brachial Index & & & & \\
Right & $1.07 \pm 0.25$ & $1.08 \pm 0.27$ & $1.05 \pm 0.22$ & 0.133 \\
Left & $1.04 \pm 0.24$ & $1.05 \pm 0.27$ & $1.02 \pm 0.19$ & 0.126 \\
& $\mathbf{n}(\%)$ & $\mathbf{n}(\%)$ & $\mathbf{n}(\mathbf{( \% )}$ & $\mathbf{p}$ \\
Hypertension & $159(61.4)$ & $92(60.1)$ & $67(63.2)$ & 0.617 \\
Dyslipemia & $155(60.1)$ & $89(58.2)$ & $66(62.9)$ & 0.450 \\
\hline
\end{tabular}

LL: Lower limbs; BP: blood pressure; $\mathrm{SaO}_{2}$ : Oxygen saturation.

The maximum value was taken in the variables: Systolic brachial BP (seated and supine), Diastolic brachial BP (seated) and $\mathrm{SaO}_{2}$ index finger.

Table 2. Clinical variables according to the diagnosis of lower extremity artery disease

\begin{tabular}{|c|c|c|c|}
\hline & $\begin{array}{l}\text { LEAD No } \\
(\mathrm{n}=485)\end{array}$ & $\begin{array}{l}\text { LEAD Yes } \\
(\mathrm{n}=109)\end{array}$ & $\mathrm{p}$ \\
\hline & Mean \pm SD & Mean \pm SD & \\
\hline Age (years) & $62.6 \pm 10.9$ & $63.5 \pm 11.2$ & 0.180 \\
\hline Body Mass Index $\left(\mathrm{kg} / \mathrm{m}^{2}\right)$ & $31 \pm 6.3$ & $30.3 \pm 6.4$ & 0.100 \\
\hline Waist circumference $(\mathrm{cm})$ & $101.5 \pm 14.5$ & $100.7 \pm 15.1$ & 0.427 \\
\hline \multicolumn{4}{|l|}{ Systolic BP in LL ( $\mathrm{mmHg}$ ) } \\
\hline Right & $169.3 \pm 39.7$ & $139.3 \pm 32.4$ & $<0.001$ \\
\hline Left & $166.5 \pm 38.5$ & $133.2 \pm 27.0$ & $<0.001$ \\
\hline \multicolumn{4}{|l|}{ Seated brachial BP (mmHg) } \\
\hline Systolic & $143.5 \pm 20.1$ & $149.9 \pm 21.4$ & $<0.001$ \\
\hline Dyastolic & $79.1 \pm 9.6$ & $79.6 \pm 11.0$ & 0.538 \\
\hline \multicolumn{4}{|c|}{ Supine systolic brachial BP (mmHg) } \\
\hline Maximum & $144.6 \pm 20.3$ & $154.0 \pm 21.6$ & $<0.001$ \\
\hline \multicolumn{4}{|l|}{ Pedial pulse (n (\%)) } \\
\hline Right & $320(89.6 \%)$ & $220(92.8 \%)$ & 0.185 \\
\hline Left & $323(90.7 \%)$ & $221(93.2 \%)$ & 0.275 \\
\hline \multicolumn{4}{|l|}{ Posterior tibial pulse (n (\%)) } \\
\hline Right & $305(85.9 \%)$ & $215(90.7 \%)$ & 0.080 \\
\hline Left & $306(85.7 \%)$ & $215(90.7 \%)$ & 0.069 \\
\hline \multicolumn{4}{|l|}{$\mathrm{SaO}_{2}$ in $\mathrm{UL}(\%)$} \\
\hline Maximum & $96.2 \pm 2$ & $96.3 \pm 2.1$ & 0.755 \\
\hline \multicolumn{4}{|l|}{$\mathrm{SaO}_{2}$ in LL supine $(\%)$} \\
\hline Right & $96.3 \pm 2.6$ & $96.2 \pm 3.0$ & 0.783 \\
\hline Left & $96.3 \pm 2.7$ & $96.3 \pm 2.7$ & 0.781 \\
\hline \multicolumn{4}{|c|}{$\mathrm{SaO}_{2}$ at $30 \mathrm{~cm}$ LL elevation (\%) } \\
\hline Right & $95.5 \pm 4.1$ & $95.5 \pm 3.5$ & 0.841 \\
\hline Left & $95.6 \pm 3.3$ & $95.5 \pm 3.9$ & 0.870 \\
\hline LDL-cholesterol & $98.2 \pm 32.1$ & $98.3 \pm 41.6$ & 0.354 \\
\hline Total cholesterol & $173.5 \pm 40.8$ & $177.2 \pm 45.5$ & 0.991 \\
\hline HbA1c & $8.2 \pm 1.7$ & $8.3 \pm 1.8$ & 0.938 \\
\hline Hypertension & $117(64.3)$ & $42(54.5)$ & 0.141 \\
\hline Dyslipidemia & $109(59.9)$ & $46(60.5)$ & 0.924 \\
\hline
\end{tabular}

Regarding BP, it has been reported that arterial hypertension is a powerful risk factor for vascular complications such as ischemic heart disease or cerebrovascular disease [34]. In Spain, it has been estimated a $33 \%$ prevalence of hypertension among the general adult population [35].

In the studied sample, mean values of systolic and diastolic BP are respectively within the range of hypertension according to the classification of the European Societies of Hypertension and Cardiology [36]. In the present study, both systolic BP and diastolic BP were higher in men and significantly higher in older patients, which is consistent with the
ERICE study on the main cardiovascular risk factors in our country, which indicates that the prevalence of hypertension is considerably higher in men at younger ages (20-44 years) and somewhat higher in women from 65 years of age. In both cases, the prevalence of hypertension increases progressively with age [33].

Table 3. Concordance, correlation and validity of indices derived from pulse oximetry with ankle-brachial index for the diagnosis of lower extremity artery disease

\begin{tabular}{|c|c|c|c|c|}
\hline \multirow[t]{2}{*}{ MEASUREMENT } & \multicolumn{2}{|l|}{ TTF } & \multicolumn{2}{|l|}{ T30-T0 } \\
\hline & $\mathrm{r}$ & $\mathrm{p}$ & $\mathrm{r}$ & $\mathrm{p}$ \\
\hline \multirow[t]{2}{*}{ Correlation with ABI } & -0.006 & NS & 0.013 & NS \\
\hline & AUC & $95 \%$ IC & AUC & $95 \%$ IC \\
\hline \multirow[t]{2}{*}{ AUC (95\% CI) } & 0.525 & $0.476-0.573$ & 0.504 & $0.454-0.553$ \\
\hline & Kappa & $95 \%$ CI & Kappa & $95 \%$ CI \\
\hline \multirow[t]{2}{*}{ Kappa Index } & 0.033 & $-0.030-0.095$ & -0.021 & $-0.076-0.033$ \\
\hline & \multicolumn{2}{|c|}{$\%(95 \% \mathrm{CI})$} & \multicolumn{2}{|c|}{$\%(95 \% \mathrm{CI})$} \\
\hline Sensitivity (\%) & \multicolumn{2}{|c|}{$22.7(17.6-28.7)$} & \multicolumn{2}{|c|}{$34.9(28.81-41.67)$} \\
\hline Specificity (\%) & \multicolumn{2}{|c|}{$84.1(79.8-87.7)$} & \multicolumn{2}{|c|}{$69.2(63.8-74.1)$} \\
\hline $\operatorname{VPP}(\%)$ & \multicolumn{2}{|c|}{$49.1(39.4-58.8)$} & \multicolumn{2}{|c|}{$43.5(36.2-51.1)$} \\
\hline PPV (\%) & \multicolumn{2}{|c|}{$61.8(57.3-66.2)$} & \multicolumn{2}{|c|}{$61.0(55.8-65.9)$} \\
\hline NPV (\%) & \multicolumn{2}{|c|}{$1.4(1.0-2.0)$} & \multicolumn{2}{|c|}{$1.1(0.9-1.5)$} \\
\hline LHR+ (\%) & \multicolumn{2}{|c|}{$0.9(0.8-1.0)$} & \multicolumn{2}{|c|}{$0.9(0.83-1.06)$} \\
\hline LHR- (\%) & \multicolumn{2}{|c|}{$22.7(17.6-28.7)$} & \multicolumn{2}{|c|}{$34.9(28.81-41.67)$} \\
\hline PPV (\%) & \multicolumn{2}{|c|}{$87.2(85.1-89.3)$} & \multicolumn{2}{|c|}{$87.1(84.9-89.2)$} \\
\hline NPV (\%) & \multicolumn{2}{|c|}{$1.3(0.8-2.1)$} & \multicolumn{2}{|c|}{$0.8(0.4-1.5)$} \\
\hline LHR+ (\%) & \multicolumn{2}{|c|}{$0.97(0.91-1.03)$} & \multicolumn{2}{|c|}{$1.02(0.97-1.07)$} \\
\hline LHR- (\%) & \multicolumn{2}{|c|}{$0.03(-0.03-0.08)$} & \multicolumn{2}{|c|}{$-0.02(-0.07-0.03)$} \\
\hline
\end{tabular}

AUC: Area under the curve; ABI: Ankle-brachial index; TTF: Toe to finger oxygen saturation difference; T30-T0: Oxygen saturation difference of great toe at $30 \mathrm{~cm}$ elevation vs. supine position. NS: not significant. LHH +: Likelihood Ratio +; LHR-: Likelihood Ratio; PPV: positive predictive value; NPV: negative predictive value; $\mathrm{CI}$ : confidence interval.

Table 4. ROC curve and AUC of the indices derived from pulse oximetry to predict lower extremity artery disease related to the ankle-brachial index. Analysis according to sex and age

\begin{tabular}{lllll}
\hline ROC CURVE & TTF & \multicolumn{3}{l}{ T30-T0 } \\
\cline { 2 - 5 } & AUC & $95 \%$ CI & AUC & $95 \%$ CI \\
\hline Global & 0.525 & $0.476-0.573$ & 0.504 & $0.454-0.553$ \\
Age & & & & \\
$\leq 65$ years & 0.569 & $0.503-0.635$ & 0.508 & $0.439-0.577$ \\
$>$ 65 years & 0.485 & $0.413-0.557$ & 0.520 & $0.447-0.593$ \\
Sex & & & & \\
Men & 0.554 & $0.488-0.621$ & 0.493 & $0.425-0.562$ \\
Women & 0.493 & $0.422-0.564$ & 0.516 & $0.444-0.589$
\end{tabular}

TTF: Great toe to index finger oxygen saturation difference; T30-T0: Oxygen saturation difference of great toe at $30 \mathrm{~cm}$ elevation vs. supine position; AUC: Area under the curve; $\mathrm{CI}$ : confidence interval.

Regarding the diagnosis of LEAD, it was established using the ABI with a 0.90 cut-off point, since it has shown a high sensitivity and specificity to detect LEAD [8]. To this regard, the frequency of LEAD found is lower than the published by other authors [37-38], which could be partially explained by the fact that the studied sample had no diagnosis of cardiovascular disease.

Related to pulse oximetry, it is normally used for medical conditions requiring constant monitoring of 
blood gases in areas such as intensive care units, emergency medicine and anesthesia. However, in previous studies it has been proposed as an indirect indicator of tissue perfusion used in the treatment of ischemic lesions in lower limbs [39] and as an alternative to ABI in the screening of LEAD [27-28] with contradictory results. In our country, other authors have analyzed its usefulness in the screening of carotid atherosclerosis in type 2 diabetics, comparing this test with carotid ultrasound and $\mathrm{ABI}$ [29]. In this study, no differences were observed in pulse oximetry based on the presence or absence of carotid plaques evaluated by ultrasound, thus lacking usefulness in the screening of carotid atherosclerosis. More recently Ena et al. found that pulse oximetry in diabetic patients did not have enough sensitivity to detect LEAD [40]. Nevertheless, studies outside our country have observed a greater sensitivity of pulse oximetry compared to $\mathrm{ABI}$ in type 2 diabetics aiming that the combination of both tests (ABI and pulse oximetry) could increase the sensitivity obtained [41]. Similarly, it has been suggested that in patients with symptomatic LEAD pulse oximetry could have as much precision as ABI [42].

Regarding the concordance between pulse oximetry and $\mathrm{ABI}$, we have not detected significant correlations between $\mathrm{SaO}_{2}$ values and $\mathrm{ABI}$ except in the ABI vs. T30-T0 in patients under 40 years of age in whom a low positive correlation was observed (Spearman's Rho $=0.343 ; \mathrm{p}=0.02$ ), in agreement with other authors [29, 43]. Regarding the differences analyzed, the mean value of $\mathrm{SaO}_{2}$ obtained in the supine position (lower limb at no elevation) was 96.4 $\pm 2.4 \%$, while with the lower limb at $30 \mathrm{~cm}$ elevation it was $95.9 \pm 2.5 \%$. The mean of the TTF was $0.19 \pm 2.3 \%$ and $-0.45 \pm 1.8 \%$ for the T30-T0. As in the study by Pellitero et al.[29] in our case we have also not observed statistically significant differences for the differences considered (TTF and T30-T0) or significant correlations of the $\mathrm{SaO}_{2}$ values with the ABI.

\section{Limitations}

One of the main limitations of $\mathrm{ABI}$ in diabetic patients is the frequent presence of arterial calcifications in the lower limbs, obtaining abnormally high values, but, on the other hand, diabetic subjects can obtain a great benefit from its measurement. Regarding pulse oximetry, some situations or external factors can cause uncertain results or incorrect readings to be obtained, such as interference with other electrical devices, strong ambient light (fluorescent), a decrease in body temperature, hypotension or vasoconstriction, and presence of dyshemoglobinemia [44].

\section{Selection biases}

Selection biases may arise from the inclusion and exclusion criteria determined for the execution of the study. In this case, no data was collected from participants who refused to participate, this percentage being less than 5\%, with which we consider that the representativeness of the sample has not been affected.

\section{Information biases}

Information biases that arise from how the data were obtained can occur.

Variability produced by the type of procedure or test used to perform the exams.

These biases were minimized, to the extent possible, through the establishment of validated questionnaires, calibrated instruments, experienced personnel, and repeated measurements.

\section{Confusion biases}

Due to the absence of variables in the data collection that should have been taken into account for the realization of this study and that are not included due to ignorance of them.

To minimize this bias, a multivariate logistic regression analysis will be performed.

\section{Conclusions}

Pulse oximetry showed little association with ABI in the diagnostic of LEAD. A relationship between LEAD and age has been found. Its diagnosis was associated with a lower body mass index and lower systolic blood pressure in the lower extremities and higher in the upper extremities. We conclude that pulse oximetry is not useful in screening for asymptomatic LEAD in type 2 diabetics.

\section{Author Contributions}

Data collection: A. M.-F.; conception and design of the study: A. M.-F.; D. B.-G.; M G.-S.; M. V-C; anlysis of data V.B.-B.; the writing of the article or the critical review of a substantial part of its content $A$. M.-F.; D. B.-G.; M G.-S.; V. B.-B.; M.V.-C.; C.G.-M.

\section{Competing Interests}

The authors have declared that no competing interest exists.

\section{References}

1. American Diabetes Association. Classification and diagnosis of diabetes. Standards of medical care in diabetes 2020. Diabetes Care. 2020; 43(Suppl 1):S14-S31.

2. Ogurtsova K, da Rocha Fernandes JD, Huang Y, Linnenkamp U, Guariguata L, Cho NH et al. IDF Diabetes Atlas: Global estimates for the prevalence of diabetes for 2015 and 2040. Diabetes Res Clin Pract. 2017; 128:40-50.

3. Centers for Disease Control and Prevention. National Center for Chronic Disease Prevention and Health Promotion. National Diabetes Statistics Report, 2020: Estimates of Diabetes and Its Burden in the United States. [acceso 15 de 
febrero de 2020]. Disponible en http://www.cdc.gov/diabetes/pdfs/data/ statistics/national-diabetes-statistics-report.pdf.

4. American Diabetes Association. Peripheral arterial disease in people with diabetes. Consensus Statement. Diabetes Care. 2003; 26(12):3333-41.

5. Bronas UG, Treat D. Peripheral artery disease in the elderly: Prevalence, clinical implications and therapy. Curr Cardiovasc Risk Rep. 2011; 5(5):457466

6. Hirsch A, Criqui MH, Treat D, Regensteiner JG, Creager MA, Olin JW et al. Peripheral arterial disease detection, awareness, and treatment in primary care. JAMA. 2001; 286(11):1317-1324.

7. Criqui M, Coughlin S, Fronek A. Noninvasively diagnosed peripheral arterial disease as a predictor of mortality: results from a prospective study. Circulation. 1985; 72(4):768-773.

8. Fowkes FG, Rudan D, Rudan I, Aboyans V, Denenberg JO, McDermott MM et al. Comparison of global estimates of prevalence and risk factors for peripheral artery disease in 2000 and 2010: a systematic review and analysis. Lancet. 2013; 382(9901):1329-1340.

9. Nativel M, Potier L, Alexandre L, Baillet-Blanco L, Ducasse E, Velho G et al. Lower extremity arterial disease in patients with diabetes: a contemporary narrative review. Cardiovasc Diabetol. 2018; 17(1):138.

10. Sampson UK, Fowkes FG, McDermott MM, Criqui MH, Aboyans V, Norman PE et al. Global and regional burden of death and disability from peripheral artery disease: 21 world regions, 1990 to 2010. Glob Heart. 2014; 9(1):145-158.

11. Monreal M, Álvarez L, Vilaseca B, Coll R, Suárez C, Toril J et al. Clinical outcome in patients with peripheral artery disease. Results from a prospective registry (FRENA). Eur J Intern Med. 2008; 19(3):192-197.

12. Suárez C, Cairols M, Castillo J, Esmatjes E, Sala J, Llobet X et al. Control de factores de riesgo y tratamiento de la aterotrombosis. Registro REACH España. Med Clin. 2007; 129(12):446-450.

13. Guijarro C, Mesa N, Jiménez J, Puras E, Sánchez C, Fernández FJ et al. Similitudes y diferencias entre los pacientes con aterosclerosis sintomática de distintos territorios. Cohorte AIRVAG (Atención Integral al Riesgo Vascular Global). Med Clin. 2006; 127(16):605-611.

14. Manzano L, García JD, Gómez J, Mateos J, del Valle FJ, Medina J et al. Valor de la determinación del índice tobillo-brazo en pacientes de riesgo vascular sin enfermedad aterotrombótica conocida: estudio VITAMIN. Rev Esp Cardiol. 2006; 59(7):662-670.

15. Bundó $\mathrm{M}$, Muñoz $\mathrm{L}$, Pérez $\mathrm{C}$, Montero JJ Montellá $\mathrm{N}$, Toran $\mathrm{P}$ et al. Asymptomatic peripheral arterial disease in type 2 diabetes patients: A 10year follow-up study of the utility of the ankle brachial index as a prognostic marker of cardiovascular disease. Ann Vasc Surg. 2010; 24(8): 985-993.

16. Puras E, Gutiérrez M, Cáncer S, Alfayate JM, de Benito L, Perera M et al. Estudio de prevalencia de la enfermedad arterial periférica y diabetes en España. Angiologia. 2008; 60(5):317-326.

17. Mostaza JM, Suárez C, Manzano L, Cairols M, López-Fernández F, Aguilar I et al. Merito Study Group. Sub-clinical vascular disease in type 2 diabetic subjects: relationship with chronic complications of diabetes and the presence of cardiovascular disease risk factors. Eur J Intern Med. 2008; 19(4): 255-260

18. Escobar C, Blanes I, Ruiz A, Vinuesa D, Montero M, Rodríguez M et al. Prevalence and clinical profile and management of peripheral arterial disease in elderly patients with diabetes. Eur J Intern Med. 2011; 22(3): 275-281.

19. Lahoz C, Mostaza JM. Índice tobillo-brazo: una herramienta útil en la estratificación del riesgo cardiovascular. Rev Esp Cardiol. 2006; 59(7):647-649.

20. American Diabetes Association (ADA). Microvascular complications and foot care. Standards of medical care in diabetes 2020. Diabetes Care. 2020; 43(Suppl 1):S135-S151.

21. Wyman RA, Keevil JG, Busse KL, Aeschlimann SE, Korcarz CE, Stein JH. Is the ankle-brachial index a useful screening test for subclinical atherosclerosis in asymptomatic, middle-aged adults?. WMJ. 2006; 105(6):50-54.

22. Bagheri R, Schutta M, Cumaranatunge RG, Wolfe ML, Terembula K, Hoffman $B$ et al. Value of electrocardiographic and ankle-brachial index abnormalities for prediction of coronary atherosclerosis in asymptomatic subjects with type 2 diabetes mellitus. Am J Cardiol. 2007; 99(7):951-955.

23. Gregg EW, Sorlie P, Paulose-Ram R, Gu Q, Eberhardt MS, Wolz M et al, Prevalence of lower-extremity disease in the US adult population $\geq 40$ years of age with and without diabetes: 1999-2000 national health and nutrition examination survey. Diabetes Care. 2004; 27(7):1591-1597.

24. Xu D, Zou L, Xing Y, Hou L, Wei Y, Zhang J, Qiao Y, Hu D, Xu Y, Li J, Ma Y. Diagnostic value of ankle-brachial index in peripheral arterial disease: a metaanalysis. Can J Cardiol. 2013;29:492-498.

25. Aboyans V, Criqui MH, Abraham P, Allison MA, Creager MA, Diehm C, Fowkes FG, Hiatt WR, Jonsson B, Lacroix P, Marin B, McDermott MM, Norgren L, Pande RL,Preux PM, Stoffers HE, Treat-Jacobson D. Measurement and interpretation of the ankle-brachial index: a scientific statement from the American Heart Association. Circulation. 2012; 126:2890-2909.

26. Grenon SM, Gagnon J, Hsiang Y. Ankle- brachial index for assessment of peripheral arterial disease. N Engl J Med, 2009; 361(19):e40.

27. Joyce W, Walsh K, Gough D, Gorey T, Fitzpatrick J. Pulse oximetry: a new non-invasive assessment of peripheral arterial occlusive disease. Br J Surg 1990; 77(10):1115-1117.

28. Parameswaran GI, Brand K, Dolan J. Pulse oximetry as a potential screening tool for lower extremity arterial disease in asymptomatic patients with diabetes mellitus. Arch Inter Med. 2005; 165(4):442-446.
29. Pellitero S, Reverter JL, Pizarro E, Granada ML, Aguilera E, Sanmartí A. Usefulness of pulse oximetry in screening of carotid atherosclerosis in patients with type 2 diabetes mellitus. Med Clin. 2010; 135(1):15-20.

30. Tendera M, Aboyans V, Bartelink ML, Baumgartner I, Clément D, Collet JP et al. ESC Guidelines on the diagnosis and treatment of peripheral artery diseases: Document covering atherosclerotic disease of extracranial carotid and vertebral, mesenteric, renal, upper and lower extremity arteries: the Task Force on the diagnosis and treatment of peripheral artery diseases of the European Society of Cardiology (ESC). Eur Heart J. 2011; 32(22): 2851-2906.

31. Rubio M, Salas J, Barbany M, Moreno B, Aranceta J, Bellido D et al. Consenso SEEDO 2007 para la evaluación del sobrepeso y la obesidad y el establecimiento de criterios de intervención terapéutica (versión íntegra). Rev Esp Obes. 2007; :7-48.

32. Aranceta J, Serra L, Foz M, Moreno B. Prevalencia de obesidad en España. Med Clin. 2005; 125(12):460-6

33. Gabriel R, Alonso M, Segura A, Tormo MJ, Artigao LM, Banegas JR, et al. Prevalencia, distribución y variabilidad geográfica de los principales factores de riesgo cardiovascular en España. Análisis agrupado de datos individuales de estudios epidemiológicos poblacionales: estudio ERICE. Rev Esp Cardiol. 2008; 61(10):1030-1040

34. Cordero A, Moreno J, Alegria E. Hipertensión arterial y síndrome metabólico. Rev Esp Cardiol. 2005; 5:38D-45D

35. Brotons C, Alemán JJ, Banegas JR, Fondón C, Lobos JM, Martín E et al. Recomendaciones preventivas cardiovasculares. Actualización PAPPS 2018. Aten Primaria. 2018; 50(Suppl 4):4-28.

36. Williams B, Mancia G, Spiering W, Agabiti E, Azizi M, Burnier M et al. Guía ESC/ESH 2018 sobre el diagnóstico y tratamiento de la hipertensión arterial. Rev Esp Cardiol. 2019; 72(2):160.e1-e78.

37. Baena JM, Alzamora MT, Forés R, Pera G, Torán P, Sorribes M. Ankle-brachial index improves the classification of cardiovascular risk: PERART/ARTPER Study. Rev Esp Cardiol. 2011; 64(3):186-92.

38. González JM, Piniés JA, Calle A, Saavedra A, Sánchez C, Bellido D, et al. Cardiovascular risk factor management is poorer in diabetic patients with undiagnosed peripheral arterial disease than in those with known coronary heart disease or cerebrovascular disease. Results of a nationwide study in tertiary diabetes centres. Diabet Med. 2008; 25(4):427-34.

39. Bianchi J, Zamiri M, Loney M, McIntosh H, Dawe R, Douglas W. Pulse oximetry index: a simple arterial assessment for patients with venous disease. J Wound Care. 2008; 17(6):253-60

40. Ena J, Argente CR, González Sánchez V, Algado N, Verdú G, Lozano T. Use of pocket pulse oximeters for detecting peripheral arterial disease in patients with diabetes mellitus. J Diabetes Mellitus. 2013;3(2):79-85.

41. Siao RM, So MJ, Gomez MH. Pulse oximetry as a screening test for hemodynamically significant lower extremity peripheral arterial disease in adults with type 2 diabetes mellitus. JAFES. 2018; 33(2):130-136.

42. Kwon JN, Lee WB. Utility of digital pulse oximetry in the screening of lower extremity arterial disease. J Korean Surg Soc. 2012; 82(2):94-100.

43. Jawahar D, Rachamalla HR, Rafalowski A, Ilkhani R, Bharathan T, Anandarao N. Pulse oximetry in the evaluation of peripheral vascular disease. Angiology. 1997; 48(8):721-4.

44. Pretto JJ, Roebuck T, Beckert L, Hamilton G. Clinical use of pulse oximetry: official guidelines from the Thoracic Society of Australia and New Zealand. Respirology. 2014; 19(1):38-46. 